\title{
A relação entre Hebreus e as práticas da Sinagoga: um estudo sobre o pano de fundo conceitual de Hebreus
}

\author{
The relationship between Hebrews and the practices of the Synagogue: \\ A study on the conceptual background of Hebrews
}

Adriani Milli Rodrigues*

André Luiz Vasconcelos**

\begin{abstract}
Resumo
O presente artigo tem como objetivo trazer a relação entre a epístola de Hebreus e as práticas da sinagoga para a discussão a respeito do pano de fundo conceitual desta epístola. Para que isto fosse possível, fez-se necessário realizar uma breve análise das duas principais propostas na literatura contemporânea: o médio-platonismo de Filo e o judaísmo palestino de Qumran. Tendo constatado que o Sitz im Leben de Hebreus é uma homilia pregada na sinagoga e que o autor de Hebreus valeu-se de métodos de exegese rabínica, concluiu-se que a prática da sinagoga fazia parte da imagética do autor de Hebreus. Com base nisso, é então sugerido que este fato seja levado em consideração no debate acerca de seu respectivo contexto intelectual.
\end{abstract}

\section{Palavras-chave}

Hebreus. Pano de fundo conceitual. Liturgia. Sinagoga. Descanso. Hermenêutica.

\begin{abstract}
This article aims to bring the relationship between the epistle to the Hebrews and the practices of the synagogue to the discussion of the conceptual background of this epistle. To make that possible, it was necessary to briefly analyze two main proposals in contemporary literature: Philo's Middle Platonism and Palestinian Judaism of Qumran. Having found that the Sitz im Leben of Hebrews is a homily preached in a synagogue and that the author of Hebrews used methods of the rabbinical exegesis, it was concluded that the practice of the synagogue was part of
\end{abstract}

[Texto recebido em março de 2017 e aceito em janeiro de 2018, com base na avaliação cega por pares realizada por pareceristas ad hoc]

* Docente de Teologia no Centro Universitário Adventista de São Paulo (UNASP-EC). Doutor em Teologia Sistemática (Andrews University). Mestre em Ciências da Religião (UMESP). E-mail: adriani.milli@unasp.edu.br

** Bacharel em Teologia (UNASP-EC). Pós-Graduando em Teologia Bíblica (UNASP-EC). E-mail: andreluiz-vasconcelos@hotmail.com 
the imagery of the author of Hebrews. Finally, the article suggests that this fact should be taken into account in the debate about conceptual background of Hebrews.

\section{Keywords}

Hebrews. Conceptual background. Liturgy. Synagogue. Hermeneutics.

\section{Introdução}

Um dos temas de maior interesse em estudos contemporâneos de Hebreus tem sido a análise do seu pano de fundo conceitual. ${ }^{1}$ Esta questão, "diz respeito à identificação do meio cultural e intelectual a partir do qual as ideias e temas do discurso derivam" . ${ }^{2}$ A importância de tal identificação pode ser observada na exegese, uma vez que uma mesma palavra ou imagem podem representar conceitos diferentes na medida em que possuem um contexto intelectual distinto.

Eric Mason observa que o debate acerca do pano de fundo conceitual que mais influenciou Hebreus possui uma longa história de discussão. ${ }^{3}$ Tendo isso em vista, este artigo propôs-se a inicialmente descrever e brevemente avaliar duas das principais propostas de pano de fundo conceitual, a saber, o médio platonismo de Filo e o judaísmo palestino de Qumran. Considerando que essas propostas contêm significantes fragilidades, o artigo visualiza no estudo hermenêutico da relação das práticas da sinagoga e Hebreus um interessante caminho que forneça novos subsídios para a discussão do contexto intelectual da epístola.

Com isso em mente, este artigo foi dividido em três partes. Na primeira parte, é promovido um diálogo entre as principais propostas a respeito do pano de fundo conceitual de Hebreus na literatura contemporânea. Na sequência, é proposto um paralelo entre a epístola de Hebreus e as práticas da sinagoga, tais como o estilo de pregação, o uso de imagens litúrgicas e o uso de exegese rabínica. Já na terceira parte, é levantada a questão acerca da relevância dos paralelos entre Hebreus e as práticas da sinagoga para o estudo do pano de fundo conceitual da epístola em questão.

1 MASON, Eric. Introduction. In: MASON, Eric; McCRUDEN, Kevin (Eds.). Reading the Epistle to the Hebrews: A Resource for Students. Atlanta: Society of Biblical Literature, 2011. p. 3.

2 LANE, William. Word Biblical Commentary: Hebrews 1-8. Dallas: Word Incorporated, 2002. p. ciii.

3 MASON, 2011, p. 4. 


\section{O pano de fundo conceitual de hebreus na literatura contemporânea \\ O médio-platonismo e o judaísmo palestino}

O debate sobre o pano de fundo conceitual do livro de Hebreus gira em torno de três principais propostas: (1) o pensamento médio-platônico (especialmente representado por Filo); (2) o judaísmo palestino; e (3) o gnosticismo. ${ }^{4}$ Este último, no entanto, tem sido abandonado em décadas recentes, especialmente entre os estudiosos de língua inglesa. ${ }^{5}$ Portanto, de um modo geral, este debate tem se inclinado à primeira e segunda proposta. Como observado por Attridge, ${ }^{6}$ os críticos têm reconhecido Hebreus como um herdeiro cristão de uma ou outra tradição judaica, a saber, o judaísmo helenista de Filo ou o judaísmo apocalíptico de Qumran.7

A posição filônica tem sido amplamente defendida pelos estudiosos de Hebreus. Esta posição tem sido frequentemente adotada por conta das similaridades entre a linguagem platônica de Filo e a linguagem de Hebreus, especialmente na descrição do Santuário Celestial em $\mathrm{Hb}$ 8.1-10.18. ${ }^{8}$

Moffatt, ${ }^{9}$ por exemplo, afirma categoricamente que a visão de mundo e de Deus contida em Hebreus é fundamentalmente platônica. Ceslas Spicq, ${ }^{10}$ da mesma forma, sustenta que "as características da mentalidade intelectual, literária e moral de Hebreus são aquelas mesmas de Alexandria". ${ }^{11}$ Além disto, ele afirma que o autor da epístola conhecia a obra de Filo e foi inspirado por sua retórica e temas. ${ }^{12}$ Spicq também propõe vários paralelos entre os escritos de Filo e a epístola de Hebreus. ${ }^{13}$

4 MASON, 2011, p. 4. Para ainda outras possibilidades, conferir o tópico intitulado "conceptual background" em LANE, 2002, p. ciii.

5 Para verificar os argumentos a favor deste ponto de vista, consultar ATTRIDGE, Harold. Hebrews, epistle to the. In: FREEDMAN, David. The Anchor Bible Dictionary. New York: Doubleday, 1996. v. 3. p. 103; KOESTER, Craig. Hebrews: A New Translation With Introduction and Commentary. New Haven/London: Yale University Press, 2008. p. 60. Para consultar os principais autores que comentam sobre este ponto de vista, ver LANE, 2002, p. cvi. Conferir especialmente o obra de KÄSEMANN, Ernst. The Wandering People of God: An Investigation of the Letter to the Hebrews. Minneapolis: Augsburg Publishing House, 1984.

6 ATTRIDGE, Harold. The Epistle to the Hebrews: A Commentary on the Epistle to the Hebrews. Philadelphia: Fortress Press, 1989. p. 29.

7 ATTRIDGE, 1989, p. 29.

8 Koester observa que "comparações entre Hebreus e os escritos de Filo mostram muitas similaridades na linguagem e na forma de pensamento, especialmente a distinção entre o mundos temporal e eterno" (KOESTER, 2008, p. 59). Conferir também THOMPSON, James. What has middle platonism to do with Hebreus? In: MASON, Eric; McCRUDEN, Kevin (Eds.). Reading the Epistle to the Hebrews: A Resource for Students. Atlanta: Society of Biblical Literature, 2011. p. 31.

9 MOFFATT, James. A Critical and Exegetical Commentary on the Epistle to the Hebrews. Edinburgh: T\&T Clark International, 1924. p. xxxi.

10 SPICQ, Ceslas. Le Philonisme de l'Epìtre aux Hébreux. Revue Biblique, Jerusalem, v. 57, n. 2, p. 212-242, 1950. p. 242.

11 "les caractéristiques de la mentalité intellectuelle, littéraire, morale, religieuse de Iiébr. sont celles mêmes de l'alexandrin".

12 SPICQ, 1950, p. 227.

13 SPICQ, 1950, p. 212-242. 
Um contraponto a esta perspectiva é apresentado por Ronald Williamson. ${ }^{14}$ Ele argumenta que das 157 hapax legomena que ocorrem em Hebreus, apenas 75 são encontradas nos escritos de Filo. Entretanto, 123 destas 157 também ocorrem na LXX. Já das 75 que aparecem em Filo, 61 também são encontradas na LXX, deixando somente 14 hapax legomena exclusivamente em comum entre Filo e Hebreus. ${ }^{15}$ Em outras palavras, Williamson demonstra que a semelhança entre a linguagem de Hebreus e a linguagem médio-platônica de Filo não é tão forte quanto parece. Além disso, ele acrescenta que a evidência linguística em si mesma não é suficiente para provar nem para refutar a dependência do autor de Hebreus dos escritos de Filo. ${ }^{16}$

Embora Williamson reconheça a possibilidade do autor de Hebreus ter empregado termos filônicos em seu vocabulário, ele rejeita a ideia de um conceito filo-platônico na epístola. ${ }^{17}$ De acordo com ele, além de uma análise linguística, é necessário um estudo acerca do pensamento dos dois escritores, bem como uma análise da forma com que cada um deles interpreta o Antigo Testamento. ${ }^{18}$

O segundo ponto de vista, como já mencionado, identifica o judaísmo palestino como o pano de fundo conceitual de Hebreus. A expressão "judaísmo palestino" é utilizada, basicamente, para referir-se aos sectários de Qumran e a outros grupos apocalípticos. ${ }^{19}$ Esta ênfase em Qumran se deve, em grande medida, aos temas em comum entre Hebreus e os Manuscritos do Mar Morto, tais como: o sacerdócio de Melquisedeque; o ministério dos anjos; messianismo; etc. ${ }^{20}$ Mason, ${ }^{21}$ por exemplo, destaca entre estes paralelos a cosmologia, o sacerdócio messiânico, e a figura celestial de Melquisedeque.

Um dos primeiros estudiosos a propor Qumran como o pano conceitual de Hebreus foi Yigael Yadin.22 Ele menciona que o grupo sectário de Qumran, que ele

14 Williamson sugere o pensamento místico da Merkabah como o pano conceitual de Hebreus. Consultar o artigo de WILLIAMSON, Ronald. The Background to the Epistle to the Hebrews. The Expository Times, v. 87, n. 8, 1976. p. 232-237.

15 WILLIAMSON, Ronald. Philo and the epistle of the hebrews. Leiden: E. J. Brill, 1970. p. 15.

16 WILLIAMSON, 1970, p. 18.

17 WILLIAMSON, 1970, p. 579.

18 WILLIAMSON, 1970, p. 18. Para uma visão geral da tese de Williamson, conferir as resenhas de HUGHES, Philip. The Westminster Theological Journal, 35 n. 3, 1973. p. 349-351; e de HOWARD, G. Journal of Biblical Literature, 92, n. 3, 1973. p. 464-465.

19 MASON, 2011, p. 4.

20 GUTRHIE, Donald. A carta aos Hebreus: introdução e comentário. São Paulo: Vida Nova/Mundo Cristão, 1984. p. 37-38. Tendo em vista estas relações, Gutrhie observa que: “[...] há alguma justificativa para a opinião de que a literatura e as práticas rituais de Cunrã lançam alguma luz sobre o meio-ambiente ao qual pertencem os leitores desta Epístola, embora seja questionável se algum contato direto pode ser pressuposto" (GUTRHIE, 1984, p. 38).

21 MASON, Eric. Cosmology, Messianism, and Melchizedek: Apocalyptic jewish traditions and hebrews. In: MASON, Eric; McCRUDEN, Kevin (Eds.). Reading the Epistle to the Hebrews: A Resource for Students. Atlanta: Society of Biblical Literature, 2011. p. 53-76.

22 LANE, 2002, p. cviii. 
identifica como os essênios, é "o elo perdido" para a compreensão de Hebreus. ${ }^{23}$ Philip Hughes, ${ }^{24}$ em seu comentário de Hebreus, afirma que a proposta de Yadin é sem dúvida a melhor teoria para explicar a ocasião e o propósito desta epístola. Contudo, ele observa que "não é necessário postular, como Yadin faz, que os destinatários de Hebreus tinham sido originalmente membros da comunidade de Qumran". ${ }^{25}$ Ainda de acordo com ele, apesar desta ser uma possibilidade, é igualmente possível que os cristãos hebreus a quem a carta foi dirigida tivessem, de uma forma ou de outra, entrado em contato com os ensinamentos desta seita. ${ }^{26}$

Entretanto, apesar de haver pontos em comum entre os manuscritos do Mar Morto e a epístola de Hebreus, também existem pontos de divergência. Segundo Lawrence Schiffman, ${ }^{27}$ existem diferenças significativas entre Hebreus e Qumran, conforme demonstrado na comparação que ele faz entre os conceitos de Templo, sacrifício e sacerdócio, presentes em ambos. ${ }^{28}$ Schiffman ${ }^{29}$ conclui que "Hebreus é, portanto, diametralmente oposto à teologia cultual da seita de Qumran"..$^{30}$ Ele também argumenta que "apesar de seu tema ritual, Hebreus é um livro cristão; já os manuscritos de Qumran, a despeito de seu messianismo apocalíptico, são escritos judaicos" ${ }^{31}$

William Lane, ${ }^{32}$ assim como Schiffman, reconhece estas diferenças ao comentar que os manuscritos do Mar Morto foram escritos em hebraico e aramaico, e que eles são semitas em sua concepção, enquanto que Hebreus foi escrito em um grego excepcional, com características do judaísmo helenista. Então, com isto em mente, ele declara que "não há base sólida para afirmar que Qumran fornece o pano de fundo conceitual para Hebreus". 33

Além destas duas principais propostas, há uma tendência de se reconhecer não somente uma, mas uma variedade combinada de influências sobre o autor de Hebreus,

23 YADIN, Yigael. The Dead Sea scrolls and the epistle to the Hebrews. In: RABIN, Chaim; YADIN, Yigael (Eds.). Scripta Hierosolymitana: aspects of the Dead Sea scrolls. Jerusalem: Magnes Press, 1958. v. 4. p. 38.

24 HUGHES, Philip. A commentary on the Epistle to the Hebrews. Grand Rapids: William. B. Eerdmans Publishing, 1987. p. 14.

25 "It is unnecessary to postulate, as Yadin does, that the recipients of Hebrews had themselves originally been members of the Qumran community".

26 HUGHES, 1987, p. 14.

27 SCHIFFMAN, Lawrence. Temple, Sacrifice and Priesthood in the Epistle to the Hebrews. In: MARTÍNEZ, Florentino García (Ed.). Echoes from the Caves: Qumran and the New Testament and the Dead Sea Scrolls. Leiden/Boston: Brill, 2009. p. 165-176.

28 Uma destas diferenças, a título de exemplo, é a expectativa sacerdotal de cada um deles. Os escritos de Qumran, de um modo geral, aguardavam um messias sacerdotal que fosse da linhagem de Zadoque, enquanto que, para o autor de hebreus, Jesus pertencia à ordem de Melquisedeque. SCHIFFMAN, 2009, p. 172.

29 SCHIFFMAN, 2009, p. 176.

30 "Hebrews is, therefore, diametrically opposed to the cultic theology of the Qumran sect".

31 "Despite its ritual theme, Hebrews is Christian; despite its apocalyptic messianism, the Qumran scrolls are Jewish".

32 LANE, 2002, cviii.

33 "There is no sound basis for affirming that Qumran provides the conceptual background for Hebrews". 
provenientes tanto do médio-platonismo como da apocalíptica judaica. Mason, ${ }^{34}$ por exemplo, menciona que o judaísmo apocalítico de Qumran provê um importante pano conceitual de hebreus, embora ele reconheça que o autor da epístola tenha utilizado ideias procedentes de uma tradição filosófica. ${ }^{35} \mathrm{Ou}$ seja, embora Mason atribua um peso maior à influência de Qumran, ele também assume um certo grau de influência do pensamento platônico.

De modo semelhante, James Thompson ${ }^{36}$ menciona que, apesar do autor de Hebreus manter uma tradição apocalíptica, ele a interpreta em termos platônicos. Ele ainda argumenta que autor de Hebreus uniu o pensamento apocalíptico com a ontologia platônica. ${ }^{37}$ Desta maneira, tanto Mason quanto Thompson reconhecem mais de uma tradição intelectual como pano de fundo conceitual para a epístola, com a diferença de que Mason destaca primariamente a influência do judaísmo palestino e Thompson ressalta em primeira instância a influência do médio-platonismo de Filo.

\section{Avaliação geral destas propostas}

Como já indicado, a temática do pano conceitual de Hebreus tem orbitado entre a proposta do médio-platonismo e do judaísmo palestino, ou até mesmo, uma combinação de ambas as influências. Também foi observado, com base na argumentação de Williamson, que a proposta médio-platônica parece pouco provável. Esta implausibilidade também é apontada por Richard Davidson. De acordo com ele, existem pelo menos cinco razões hermenêuticas para discordar da proposta médio-platônica de Filo:

(1) o autor de Hebreus não usa a suposta terminologia platônica [tupos/antitupos] num modelo compatível com o do filósofo. (2) O mundo celestial das ideias de Platão e Filo - o qual não pode ser adestrado, salvo pela razão - não tem lugar para a pessoa histórica de Jesus, da forma como foi descrita pelo autor de Hebreus. (3) A sequência de movimento históricotemporal em Hebreus é totalmente incompatível com os princípios eternal/atemporal da ética e metafísica platônica. (4) Há alegoria, não tipologia, em Filo; e tipologia, não alegoria, em Hebreus. (5) Não há sinal de messianismo nos trabalhos de Filo, em oposição ao tema cristológico dominante em Hebreus. ${ }^{38}$

Além dos pontos que apontam para a implausibilidade da proposta médioplatônica destacada pelos argumentos acima, também foi verificado que o judaísmo

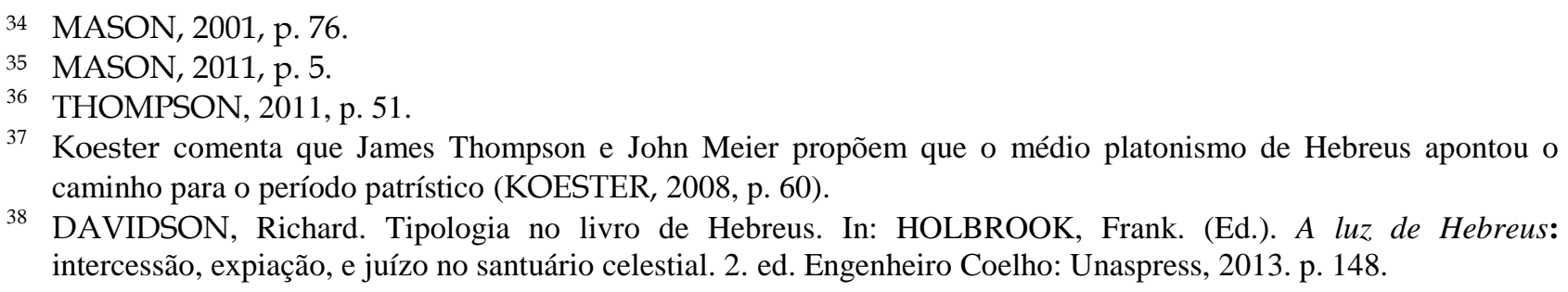

38 DAVIDSON, Richard. Tipologia no livro de Hebreus. In: HOLBROOK, Frank. (Ed.). A luz de Hebreus: intercessão, expiação, e juízo no santuário celestial. 2. ed. Engenheiro Coelho: Unaspress, 2013. p. 148. 
palestino não parece prover um pano de fundo adequado para a epístola de Hebreus, no sentido de que existem diferenças significativas entre sua cosmologia e a de Qumran, tal como observado por Schiffman e Lane. Além disso, depõe contra esta proposta o fato de que os manuscritos do Mar Morto foram escritos basicamente em hebraico e aramaico, enquanto Hebreus foi escrito em um grego de alto nível.

\section{Hebreus e as práticas da sinagoga}

Com o objetivo de analisar a relação entre Hebreus e as práticas da sinagoga, este tópico foi dividido em duas partes: (1) "estilo de pregação", onde é traçado um paralelo entre a epístola de Hebreus e as homilias que eram pregadas na sinagoga; e (2) "liturgia e exegese", onde são exploradas as imagens de Hebreus que remetem à liturgia da sinagoga, bem como o uso de princípios de hermenêutica rabínica pelo autor de Hebreus.

\section{Estilo de pregação}

Muitos autores têm reconhecido que a epístola de Hebreus se parece com um tipo de homilia. William Johnsson, ${ }^{39}$ por exemplo, identifica Hebreus como um sermão que alterna exposições teológicas com exortações práticas (I. Exposição 1.1-14, Exortação 2.1-4; II. Exposição 2.5-3.6a, Exortação 3.6b- 4.16; III. Exposição 5.1-10, Exortação 5.11-6.20; IV. Exposição 7.1-10.18, Exortação 10.19-13.25).

O próprio autor de Hebreus identifica a epístola como uma "palavra de exortação"

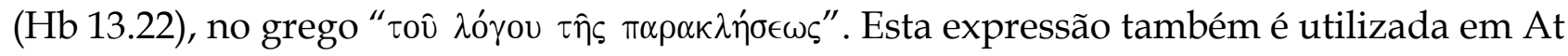
13.15 para referir-se ao sermão de Paulo pregado na sinagoga de Antioquia. Segundo At 13.15 (ARA, grifo nosso): “Depois da leitura da lei e dos profetas, os chefes da sinagoga

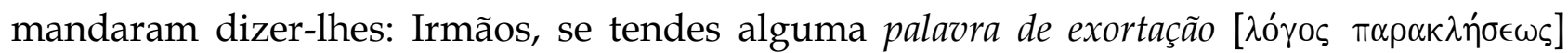
para o povo, dizei-a". A comparação entre $\mathrm{Hb} 13.22$ e At 13.15 parece indicar que o termo "palavra de exortação" era uma expressão idiomática para a homilia que era pregada após a leitura pública da Lei e dos Profetas. ${ }^{40}$

O costume da leitura pública da Lei e dos Profetas nas sinagogas, tal como em At 13.15, é atestado em outras partes do Novo Testamento (Lc 4.16;30; At 15.21); bem como na Mishná (Meguilá, 4.1-2,4); nos escritos de Josefo (Contra Apión 2.175); e nos escritos de Filo

39 JOHNSSON, William. Panorama geral de hebreus. In: HOLBROOK, Frank (Ed.). A luz de Hebreus: intercessão, expiação, e juízo no santuário celestial. 2. ed. Engenheiro Coelho: Unaspress, 2013. p. 28, 38.

40 LANE, William. Word Biblical Commentary: Hebrews 9-13. Dallas: Word Incorporated, 2002. p. 568. Esta

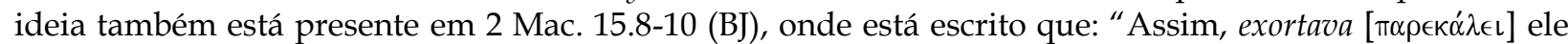
seus companheiros a não temerem o ataque dos pagãos, mas, tendo em mente os socorros já vindos a eles do céu, a esperarem, também agora, a vitória que lhes adviria da parte do Todo-Poderoso. Confortandoos então por meio da Lei e dos Profetas, e recordando-lhes também os combates que já haviam sustentado,

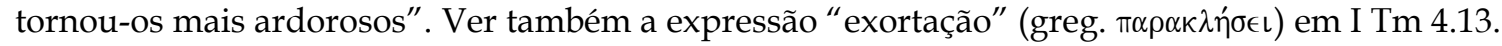


(Som 2.127). Segundo Louis Jacobs, ${ }^{41}$ esta prática poderia ter se originado por volta da primeira metade do III séc. A.E.C., uma vez que a LXX já havia sido copiada para o propósito da leitura pública na sinagoga. ${ }^{42}$

A ideia de que Hebreus é na verdade uma homilia pregada na sinagoga também é desenvolvida por Gabriella Gelardini. ${ }^{43}$ Ela identifica, inclusive, uma estrutura tripartida de Hebreus (1-6; 7.1-10.18; e 10.19-13.25) e a compara com uma prática de homilética judaica conhecida como petichta. ${ }^{44}$ Em sua leitura, os textos utilizados com base para a homilia de Hebreus foram Êx 31.18-32.35 e Jr 31.31-34. ${ }^{45}$ Como consequência disto, ela identifica o texto de Êxodo como a parashá (porção da Lei) da homilia de Hebreus, e o texto de Jeremias como sua respectiva haftará (porção dos profetas, heb. conclusão).

Havendo estabelecido a porção da parashá e da haftará, Gelardini ${ }^{46}$ localiza a homilia de Hebreus dentro do calendário litúrgico judaico, utilizando como base o ciclo trienal de leitura. ${ }^{47}$ Ela conclui que a homilia de Hebreus foi pregada entre a celebração de Tishá be-Av ${ }^{48}$ e Yom Kippur, tendo como tema da pregação a quebra da aliança (ÊEx 32 e Tishá be-Av) e sua subsequente renovação (Jr 31 e Yom Kippur).

Apesar de atraente, o argumento de Gelardini é difícil de ser sustentado, visto que a base de seu argumento está na identificação Hb 4.4 como uma citação de Êx 31.17.49 Entretanto, o autor de Hebreus parece citar Gn 2.2 e não Êx 31.17, conforme demonstrando a seguir:

41 JACOBS, Louis. Torah, reading of. In: SKOLNICK, Fred; BERENBAUM, Michael (Eds.). Encyclopaedia judaica. 2. ed. Detroit/New York: Thomson Gale, 2007. v. 20. p. 46.

42 Para uma discussão mais ampla acerca da leitura da Lei dos Profetas, conferir "Introduction". In: FISHBANE, Michael. JPS commentary: Haftarot/Philadelphia: The Jewish Publication Society, 2002.

${ }^{43}$ GELARDINI, Gabriella. Hebrews, an ancient synagogue homily for tisha be-av: its function, its basis, its theological interpretation. In: GELARDINI, Gabriella (Ed.). Hebrews: contemporary methods-new insights. Leiden/Boston: Brill, 2005. p. 107-127.

44 GELARDINI, Gabriella. Hebrews, homilects, and liturgical Scripture interpretation. In: MASON, Eric; McCRUDEN, Kevin (Eds.). Reading the Epistle to the Hebrews: A Resource for Students. Atlanta: Society of Biblical Literature, 2011. p. 135. A "petichta" ou "petihah" era um midrash aggádico, cuja estrutura básica era constituída por três partes: (1) uma introdução com a citação de um ou mais textos, geralmente da haguiografa ou dos profetas posteriores que estejam de alguma forma associados à parashá; (2) a interpretação destas citações; e (3) uma conclusão com o versículo introdutório da parashá. ENCYCLOPAEDIA HEBRAICA. Aggadah. In: SKOLNICK, Fred; BERENBAUM, Michael [Eds.]. Encyclopaedia judaica. 2. ed. Detroit/New York: Thomson Gale, 2007. v. 1. p. 457.

45 GELARDINI, 2005, p. 117-120.

46 GELARDINI, 2005, p. 120-124.

47 A referência mais antiga de um ciclo fixo de leitura da Torá e dos Profetas encontra-se no Talmud (B. Meguilá 29b) (JACOBS, 2007, p. 46). Neste texto, é mencionada a existência de dois ciclos recorrentes naquele período: um ciclo trienal, possivelmente mais antigo, e outro anual (GELARDINI, 2011, p. 128). O ciclo trienal, também conhecido como Palestino, era divido em 154 ou 167 seções semanais, as quais eram chamadas sedarim (FISCHER, Alexander. $O$ texto do Antigo Testamento: edição reformulada da Introdução à Bíblia Hebraica de Ernest Würthwein. Barueri: Sociedade Bíblica do Brasil, 2013. p. 30-31). Há evidências que este sistema de leitura era praticado na Palestina e no Egito até por volta do ano 1170 da E.C (SKOLNICK; BERENBAUM, 2007, v. 20. p. 140). Já o ciclo anual ou Babilônico, era composto por 54 sedarim (sing. sidrah ou parashá) (FISCHER, 2013, p. 30). Por conta disso, a leitura da Torá que seguia o ciclo Babilônico era completada em um ano, enquanto que a leitura que seguia o ciclo Palestino levava em média três anos (JACOBS, 2007, p. 46).

48 Tishá be-Av ou "9 de Av" é um memorial da queda dos dois Templos, o de Salomão e o de Herodes.

49 GELARDINI, 2005, p. 120. 


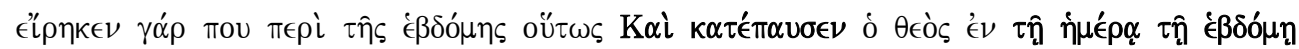

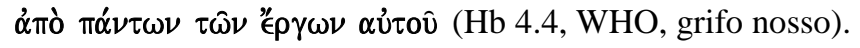

Porque, em certo lugar, assim disse, no tocante ao sétimo dia: E descansou Deus, no sétimo dia, de todas as obras que fizera (Hb 4.4, ARA, grifo nosso).

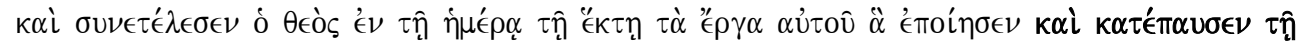

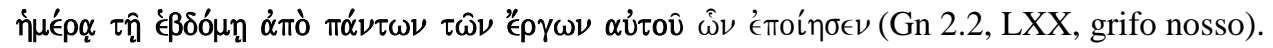

E, havendo Deus completado no sexto dia ${ }^{50}$ a sua obra, que fizera, descansou no sétimo dia de toda a sua obra que tinha feito (Gn 2.2, tradução livre).

Ainda que o argumento de Gelardini apresente falhas acerca da determinação da parashá, e como consequência disso, do calendário litúrgico, ela parece acertar quando identifica o Sitz im Leben (contexto vivencial) da epístola de Hebreus como uma reunião na sinagoga. 51

Outro autor a fazer uma associação entre Hebreus e a pregação da sinagoga é Lane. De forma semelhante a Gelardini, ele identifica Hebreus como um midrash homilético.52 Além disso, ele observa que o autor de Hebreus, assim como sua comunidade, utilizaram um texto em grego. ${ }^{53}$ Esta afirmação é especialmente evidente nos lugares onde as versões gregas mais antigas diferem do texto hebraico (por exemplo, 3.7b11, citando Ps. 95.7b-11; 10.5-7, citando Sal. 40.6-8). ${ }^{54}$ Como consequência disso, Lane ${ }^{55}$ observa que a forma da homilia de Hebreus reflete a influência da pregação de uma sinagoga judaico-helenística. Ele também assevera que "Hebreus é uma escritura judaicocristã que mantém um ethos distintamente judaico moldado pelo judaísmo helenista" ${ }^{56}$

\section{Liturgia e exegese}

O uso de imagens litúrgicas na epístola de Hebreus pode ser observado especialmente na seção 3.6b-4.16. A referência ao Salmo 95 (94 na LXX) em Hb 3.7b-11,15; 4.3b,5,7b; e a referência de $\mathrm{Gn} 2.2 \mathrm{em} \mathrm{Hb} 4.4$, remetem à liturgia de recepção do sábado na sinagoga (Kabalat Shabbat), onde a recitação do S1 95 foi seguida pela recitação de Gn 2.2.57

Lane $^{58}$ constata que o uso litúrgico do Salmo 95, como um preâmbulo dos serviços realizados nas noites de sexta nas sinagogas daquele período, já é um conceito bem

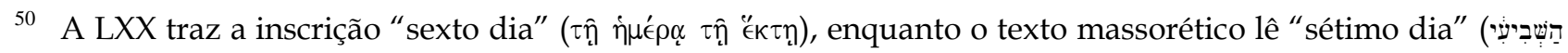
a

51 GELARDINI, 2005, p. 115.

52 LANE, 2002, p. cxxiv. George Buchanan observa que "o documento intitulado 'Aos Hebreus' é um midrash homilético baseado no Sl 110". BUCHANAN, George. W. The anchor Bible: to the hebrews. 2. ed. EUA: ABRL Doubleday, 1976. p. xix. Conferir também p. 246.

53 LANE, 2002, cxxvi.

54 LANE, 2002, p. cxxvi.

55 LANE, 2002, p. cxxvi.

56 "Hebrews is a Jewish-Christian writing that retains a distinctly Jewish ethos shaped by hellenistic Judaism".

57 LANE, 2002, p. 100.

58 LANE, 2002, p. 85. 
estabelecido. ${ }^{59}$ Já a porção de "vāykhŭllü" (Gn 2.1-3), aparece na liturgia da recepção do sábado tanto na Amida ${ }^{60}$ (Tal. B. shabbat 119b) ${ }^{61}$ como no Kidush $^{62}$ (Tal. B. pesachim 106a).

Além de utilizar o Salmo 95 e Gn 2.2, que eram porções conhecidas pelo público da sinagoga, o autor de Hebreus conecta estes dois textos utilizando um princípio de interpretação rabínico conhecido como ğêêrâ šāwâa. ${ }^{63}$ Este princípio é uma das sete midot (regras hermenêuticas) que, de acordo com a tradição judaica, foram estabelecidas pelo rabino Hillel (Tosefta, sanhedrim 7.11). Segundo Lane, ${ }^{64}$ a regra de gěêêâ šāwâa consiste em um princípio de analogia verbal, o qual permite que um versículo explique outro a partir desta relação.

Com base neste princípio de interpretação, o autor de Hebreus relaciona um texto da Torá (Gn 2.2) com um textos dos Escritos (S1 95), e possivelmente, com um texto dos Profetas Anteriores (Js 1.13;21.44;22.4), uma vez que é feita uma alusão ao "descanso"

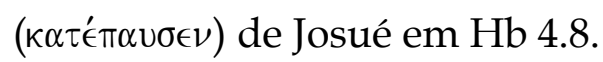

Além de Lane, autores como Attridge, ${ }^{65}$ Buchanan, ${ }^{66}$ Ellingworth, ${ }^{67}$ Gallus ${ }^{68}$ e Hebert Bateman ${ }^{69}$ têm reconhecido que o autor de Hebreus utilizou liturgicamente recursos de interpretação rabínica.

\section{A prática da sinagoga e o pano de fundo conceitual de Hebreus}

Como observado na seção anterior, é possível que o Sitz im Leben de Hebreus seja uma reunião na sinagoga, tal como argumentado por Gelardini. Também foi observado que o seu autor possivelmente tenha utilizado princípios de interpretação rabínica nos capítulos três e quatro. Apesar de estes dados serem amplamente reconhecidos, eles têm

59 De acordo com Erhard Gallus, a recitação do S1 95 e de Gn 2 já era uma prática judaica no período do Segundo Templo. GALLUS, Erhard. KATAIIAYIII and $\angle A B B A T I L M O \Sigma$ in hebrews 4. Berrien Springs, 2011. Dissertation (Doctor of philosophy) - Andrews University, Berrien Springs, 2011. p. 173.

60 A Amidah é uma oração judaica composta primeiramente por 18 bênçãos. Sua origem tem sido datada desde o período dos 120 anciãos da Grande Assembléia (Tal. B. meguila 17b; berachot 33a), isto é, o início do período do Segundo Templo, até o período do Rabban Gamaliel II após a destruição de Yavneh (Tal. B. berachot 28b) (EHRLICH, Uri. Amidah. In: SKOLNICK, Fred; BERENBAUM, Michael (Eds.). Encyclopaedia judaica. 2. ed. Detroit/New York: Thomson Gale, 2007. v. 2. p. 73). De acordo com Ronald Eisenberg, no final do Segundo Templo a recitação da Amidah tornou-se um costume geral (EISENBERG, Ronald. The JPS Guide to Jewish Traditions. Philadelphia: The Jewish Publication Society, 2004. p. 422).

61 Apesar de estas referências serem do período amoraíta, elas evidenciam que a prática de incluir uma bênção especial sobre o sábado na Amidah já era bem difundida em sua época.

62 A mishná (berachot 8.1) menciona uma disputa entre a casa de Hillel e a casa de Shammai acerca de sua recitação, demonstrando desta forma, a antiguidade deste costume.

63 LANE, 2002, p. 95.

64 LANE, 2002, p. cxxi

65 ATTRIDGE, 1989, p. 129;

66 BUCHANAN, 1976, p. 263

67 ELLINGWORTH, Paul. The Epistle to the Hebrews: A Commentary on the Greek Text. Grand Rapids: W.B. Eerdmans; Carlisle: Paternoster Press, 1993. p. 23.

68 GALLUS, 2011, p. 27.

69 BATEMAN, Hebert. Second Temple exegetical practices: extra-biblical examples of exegesis compared with those in the book of Hebrews. Southwestern Journal of Theology, v. 53, n. 1, p. 26-54, 2010. p. 26-54. 
sido trabalhados basicamente sob uma perspectiva histórica, como, por exemplo, a identificação de Hebreus como uma homilia pregada em uma sinagoga da diáspora (Lane) ou o momento em que esta homilia foi pregada dentro do calendário litúrgico judaico (Gelardini). Entretanto, pouca ênfase tem sido dada para as implicações desta prática para a identificação de um pano de fundo conceitual que se deriva de um paradigma litúrgico e hermenêutico adotado por Hebreus.

Se o autor de Hebreus possuía em seu imaginário a prática litúrgica e exegética da sinagoga (como observado em $\mathrm{Hb} 4$ ), como interpretação do Antigo Testamento, essa prática necessita ser incluída na discussão a respeito do pano de fundo conceitual de Hebreus.

Um exemplo de como a prática da sinagoga pode interferir na interpretação do texto pode ser observado nos capítulos 3-4. O uso do recurso rabínico de gězêrâ šă âwâ nestes capítulos pressupõe que haja uma relação entre Gn 2.2, S1 95 e Js. Ao adotar este princípio,

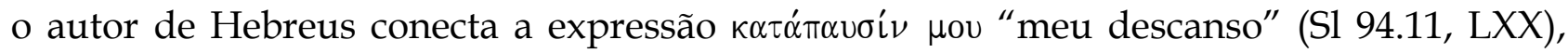

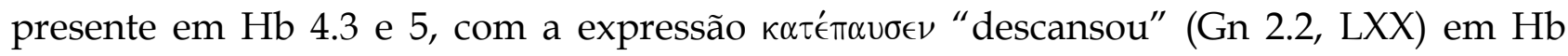
4.4. ${ }^{70}$

Tal uso de termos cognatos permitiu que um conceito que era para se referir simplesmente a uma terra a ser habitada (Josué) ganhasse contornos cosmológicos da criação (Gn 2// Hb 4.4) e escatológicos ( $\mathrm{Hb}$ 4.5-11, citando Sl 95). Como consequência desta perspectiva hermenêutica, o autor da epístola pôde inferir que o descanso de Deus na criação bem como o descanso da terra tipificam o repouso escatológico prometido ao povo de Deus.

Esta interpretação parece excluir a dependência de Filo, uma vez que ele interpreta Gn 2.2 de forma alegórica (Leg 1.16; Pos 1.64) e não de maneira tipológica como

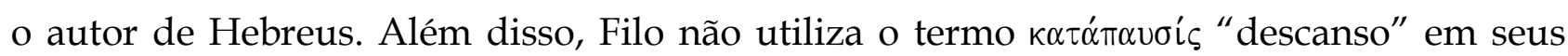

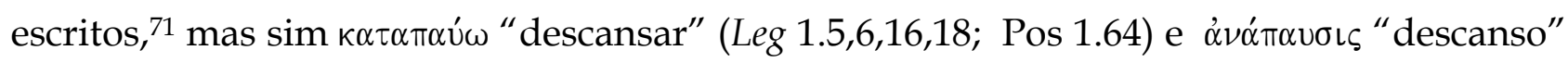
(Abr 1.28; Che 1.87; Fug 1.174) para se referir ao repouso sabático.

Se as considerações deste artigo forem válidas, um elemento importante na discussão do contexto intelectual da epístola de Hebreus seria a observação do uso de um paradigma litúrgico e hermenêutico para a articulação de conceitos presentes no Antigo Testamento. Nesse caso, o autor de Hebreus não estaria meramente derivando conceitos prontos de uma tradição intelectual existente (como Filo e/ou Qumran), mas estaria primariamente articulando conceitos a partir do corpus do Antigo Testamento por meio de

70 LANE, 2002, p. 99. Esta relação evidencia mais uma vez o uso da LXX pelo autor de Hebreus, visto que o

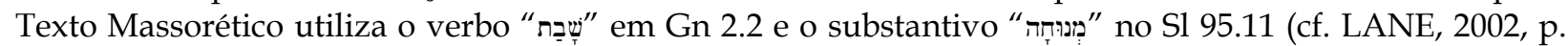
cxxi). Para um estudo mais abrangente do uso da LXX em Hebreus, conferir DOCHERTY, Susan E. The use of the Old Testament in Hebrews: A Case Study in Early Jewish Bible Interpretation.Tübingen: Mohr Siebeck, 2009. p. 121-142.

71 GALLUS, 2011, p. 148. 
uma reflexão litúrgica e hermenêutica. Nessa perspectiva, o foco da discussão sobre o contexto intelectual de Hebreus se deslocaria da ideia de mera absorção por parte do autor de conceitos prontos em tradições intelectuais da época, para uma atividade mais hermeneuticamente ativa do autor de Hebreus na articulação intelectual de conceitos com base no corpus do Antigo Testamento.

\section{Considerações finais}

Como observado no princípio deste artigo, as propostas para o pano de fundo conceitual de Hebreus têm orbitado entre o médio-platonismo e o judaísmo palestino. Contudo, foi demonstrado que ambas as propostas possuem pontos fracos. Longe de ignorar a discussão a respeito destas duas possibilidades, este artigo buscou trazer a relação entre Hebreus e as práticas da sinagoga para esta discussão. Normalmente, a discussão recente sobre a relação entre as práticas da sinagoga e Hebreus não informa o debate sobre o pano de fundo conceitual da epístola. Mas uma vez que a prática da sinagoga faz parta da imagética da epístola, conclui-se que este assunto deve ser levado em consideração na discussão a respeito da relação do contexto intelectual de Hebreus e o conteúdo da epístola.

\section{Referências}

ATTRIDGE, Harold. Hebrews, epistle to the. In: FREEDMAN, David. The Anchor Bible Dictionary. New York: Doubleday, 1996. v. 3.

. The Epistle to the Hebrews: A Commentary on the Epistle to the Hebrews.

Philadelphia: Fortress Press, 1989.

BATEMAN, Hebert. Second Temple exegetical practices: extra-biblical examples of exegesis compared with those in the book of Hebrews. Southwestern Journal of Theology, v. 53, n. 1, p. 26-54, 2010.

BUCHANAN, George. W. The anchor Bible: to the hebrews. 2. ed. EUA: ABRL Doubleday, 1976.

DAVIDSON, Richard. Tipologia no livro de Hebreus. In: HOLBROOK, Frank. (Ed.). A luz de Hebreus: intercessão, expiação, e juízo no santuário celestial. 2. ed. Engenheiro Coelho: Unaspress, 2013.

DOCHERTY, Susan E. The use of the Old Testament in Hebrews: A Case Study in Early Jewish Bible Interpretation.Tübingen: Mohr Siebeck, 2009.

EHRLICH, Uri. Amidah. In: SKOLNICK, Fred; BERENBAUM, Michael (Eds.).

Encyclopaedia judaica. 2. ed. Detroit/New York: Thomson Gale, 2007. v. 2. 
EISENBERG, Ronald. The JPS Guide to Jewish Traditions. Philadelphia: The Jewish Publication Society, 2004.

ELLINGWORTH, Paul. The Epistle to the Hebrews: A Commentary on the Greek Text. Grand Rapids: W.B. Eerdmans; Carlisle: Paternoster Press, 1993.

ENCYCLOPAEDIA HEBRAICA. Aggadah. In: SKOLNICK, Fred; BERENBAUM, Michael [Eds.]. Encyclopaedia judaica. 2. ed. Detroit/New York: Thomson Gale, 2007. v. 1.

FISCHER, Alexander. O texto do Antigo Testamento: edição reformulada da Introdução à Bíblia Hebraica de Ernest Würthwein. Barueri: Sociedade Bíblica do Brasil, 2013.

FISHBANE, Michael. JPS commentary: Haftarot/Philadelphia: The Jewish Publication Society, 2002.

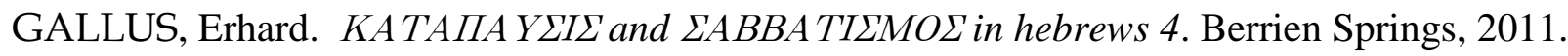
Dissertation (Doctor of philosophy) - Andrews University, Berrien Springs, 2011.

GELARDINI, Gabriella. Hebrews, an ancient synagogue homily for tisha be-av: its function, its basis, its theological interpretation. In: GELARDINI, Gabriella (Ed.). Hebrews: contemporary methods-new insights. Leiden/Boston: Brill, 2005.

. Hebrews, homilects, and liturgical Scripture interpretation. In: MASON, Eric; McCRUDEN, Kevin (Eds.). Reading the Epistle to the Hebrews: A Resource for Students. Atlanta: Society of Biblical Literature, 2011.

GUTRHIE, Donald. A carta aos Hebreus: introdução e comentário. São Paulo: Vida Nova/Mundo Cristão, 1984.

HOWARD, G. Journal of Biblical Literature, 92, n. 3, 1973.

HUGHES, Philip. A commentary on the Epistle to the Hebrews. Grand Rapids: William. B. Eerdmans Publishing, 1987. . The Westminster Theological Journal, 35 n. 3, 1973.

JACOBS, Louis. Torah, reading of. In: SKOLNICK, Fred; BERENBAUM, Michael (Eds.). Encyclopaedia judaica. 2. ed. Detroit/New York: Thomson Gale, 2007. v. 20.

JOHNSSON, William. Panorama geral de hebreus. In: HOLBROOK, Frank (Ed.). A luz de Hebreus: intercessão, expiação, e juízo no santuário celestial. 2. ed. Engenheiro Coelho: Unaspress, 2013.

KÄSEMANN, Ernst. The Wandering People of God: An Investigation of the Letter to the Hebrews. Minneapolis: Augsburg Publishing House, 1984.

KOESTER, Craig. Hebrews: A New Translation With Introduction and Commentary. New Haven/London: Yale University Press, 2008. 
LANE, William. Word Biblical Commentary: Hebrews 1-8. Dallas: Word Incorporated, 2002. Word Biblical Commentary: Hebrews 9-13. Dallas: Word Incorporated, 2002.

MASON, Eric. Comsmology, Messianism, and Melchizedek: Apocalyptic jewish traditions and hebrews. In: MASON, Eric; McCRUDEN, Kevin (Eds.). Reading the Epistle to the Hebrews: A Resource for Students. Atlanta: Society of Biblical Literature, 2011.

. Introduction. In: MASON, Eric; McCRUDEN, Kevin (Eds.). Reading the Epistle to the Hebrews: A Resource for Students. Atlanta: Society of Biblical Literature, 2011.

MOFFATT, James. A Critical and Exegetical Commentary on the Epistle to the Hebrews. Edinburgh: T\&T Clark International, 1924.

SCHIFFMAN, Lawrence. Temple, Sacrifice and Priesthood in the Epistle to the Hebrews. In: MARTÍNEZ, Florentino García (Ed.). Echoes from the Caves: Qumran and the New Testament and the Dead Sea Scrolls. Leiden/Boston: Brill, 2009.

SPICQ, Ceslas. Le Philonisme de l'Epìtre aux Hébreux. Revue Biblique, Jerusalem, v. 57, n. 2, p. 212-242, 1950.

THOMPSON, James. What has middle platonism to do with Hebrews? In: MASON, Eric; McCRUDEN, Kevin (Eds.). Reading the Epistle to the Hebrews: A Resource for Students. Atlanta: Society of Biblical Literature, 2011.

WILLIAMSON, Ronald. Philo and the epistle of the hebrews. Leiden: E. J. Brill, 1970. 1976. . The Background to the Epistle to the Hebrews. The Expository Times, v. 87, n. 8, YADIN, Yigael. The Dead Sea scrolls and the epistle to the Hebrews. In: RABIN, Chaim; YADIN, Yigael (Eds.). Scripta Hierosolymitana: aspects of the Dead Sea scrolls. Jerusalem: Magnes Press, 1958. v. 4. 